\title{
Intuitive and Formal Feedback
}

\author{
Ernest H. Forman \\ Professor of Management Science \\ George Washington University \\ Washington, D.C. 20052
}

\begin{abstract}
In some (but not necessarily all) choice decisions, there may be a dependence of objective importance on alternative preferences. This dependence can be accommodated either with formal feedback calculations or intuitively by the decision maker. This paper examines the relationship between intuitive and formal feedback.
\end{abstract}

\section{INTRODUCTION}

Suppose you are the mayor of a medium size city. The city council has just approved funding for a bridge that will connect the eastern and southern districts-- saving the residents 30 minutes in commuting time. You declare that the winning proposal will be chosen using a formal evaluation methodology and the proposals will be evaluated on the basis of strength and aesthetics. In order to be fair, you will, before receiving any bids, announce which of the two criteria will be more important. It seems obvious ${ }^{2}$ that strength is much more important than aesthetics and you publicly announce that strength will be the most important criterion in choosing the winning proposal. :

Subsequently, two alternative designs are proposed for the new bridge.

Bridge A is extremely save (as safe as any bridge yet built in the State) and beautiful. Bridge B is twice as strong as bridge A, but is UGLY!. Your hands are tied -- you have announced that the most important criterion is strength and you must choose the ugly bridge. The bridge is built and most of the town residents are reminded of your decision at least twice a day. You lose the next election.

Decisions like this, but with many more criteria ${ }^{2}$, are made all too often in everyday life. Government organizations often have regulations that mandate that criteria weights be established and announiced before a request for proposal (for alternatives) is issued. In our rather simple two

\footnotetext{
'It would be'near impossible to defend a position that the strength of the bridge is not more important than aesthetics.

${ }^{2}$ The author has found that although criteria and objectives are used interchangeably in practice (e.g., some speak of multiple criteria decision making while others speak of multiple objective decision making), there is an important difference between criteria and objectives when analyzing decisions. Criteria can be used to measure altematives on almost any conceivable dimension, but some of these dimensions may correspond to objectives of the decision makers. Use of the word objectives rather than criteria often eliminates confusion in a decision conference. We will continue to use criteria here only for the sake of consistency.
} 
criteria example, the Mayor could have easily chosen the strong, beautiful bridge intuitively had he just seen the alternatives before announcing the criteria weights. But in real world decisions, the numerous competing factors of the decision challenge man's cognitive abilities to evaluate and process the information using intuition alone. Hence we rely on decision models. An Analytic Hierarchy Process (AHP) ${ }^{3}$ model with these two criteria decision and a 'top down' evaluation approach would look like following:

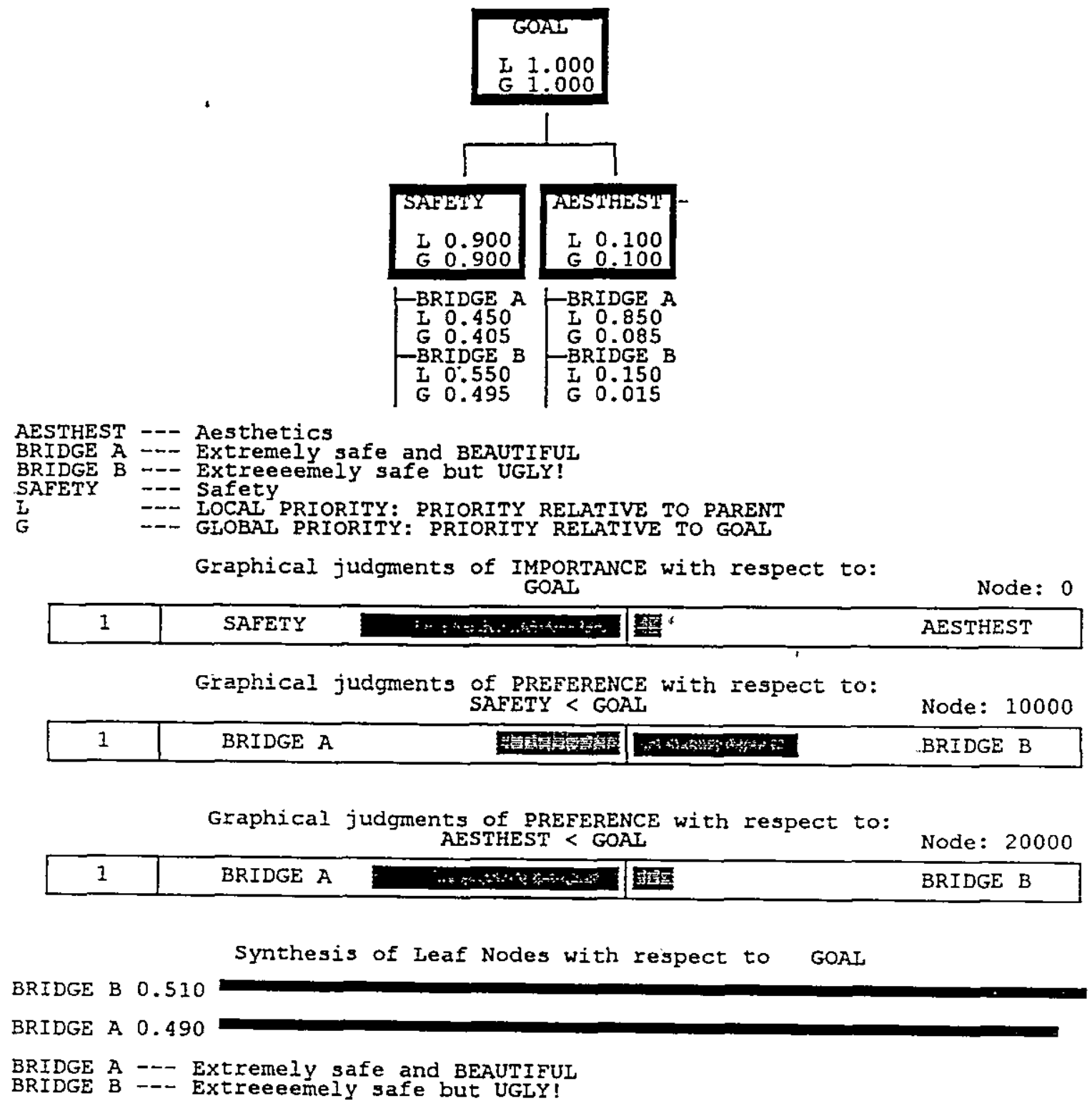

${ }^{3}$ Saaty, T.L., The Analytic Hierarchy Process, RWS Publications, Pittsburgh PA, 1990. 


\section{TOP DOWN and BOTTOM UP}

The 'top down' approach used above entails evaluating the criteria importance before evaluating the alternative preferences. A 'bottom up' approach, on the other hand, would consist of the evaluation of alternative preferences with respect to each criterion before evaluating the relative importance of the criteria. If the decision maker had used a bottom up approach instead, he/she would have learned that although design $B$ is stronger than design $A$, both designs far exceed all safety standards. Furthermore, the decision maker would have learned that design A is beautiful and while design B is ugly. Subsequently, while considering the relative importance of strength and aesthetics, the decision maker might justifiably decide that aesthetics is more important than strength. A decision maker's judgment about the relative importance of safety and aesthetics in a bottom up approach, and the resulting synthesis, indicating that Bridge $A$ is now more preferable, might look like the following:

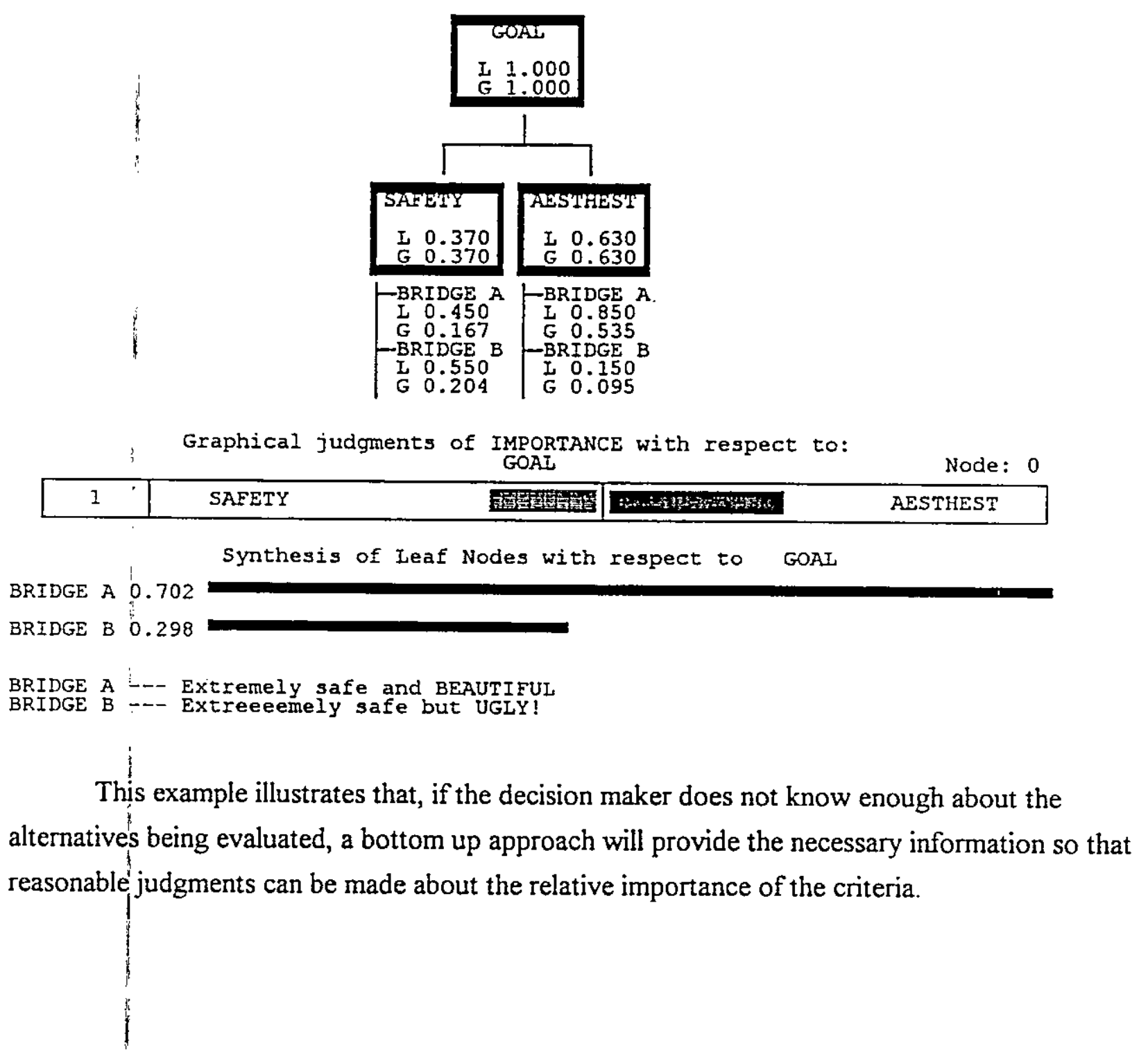


Even if a top down approach is used, no harm will result provided the decision maker examines the tentative model results and questions its reasonableness. ${ }^{4}$ In this example, the Mayor would, after synthesizing the first time realize, that the choice of the ugly bridge is counterintuitive, now knowing that both bridges are more than adequately safe, and should re-evaluate his/her judgments in the model. Doing so will result in the obviously correct choice of Bridge A.

\section{A MORE FORMAL MECHANISM -- AHP WITH FEEDBACK}

A more formal approach is to use AHP with feedback. ${ }^{5}$ An AHP model with feedback for this bridge selection example would, instead of asking the decision maker to compare the relative importance of safety and aesthetics with respect to the 'goal', instead ask for judgments about the relative importance of safety and aesthetics first with respect to Bridge $A$, and then with respect to Bridge $\mathrm{B}$.

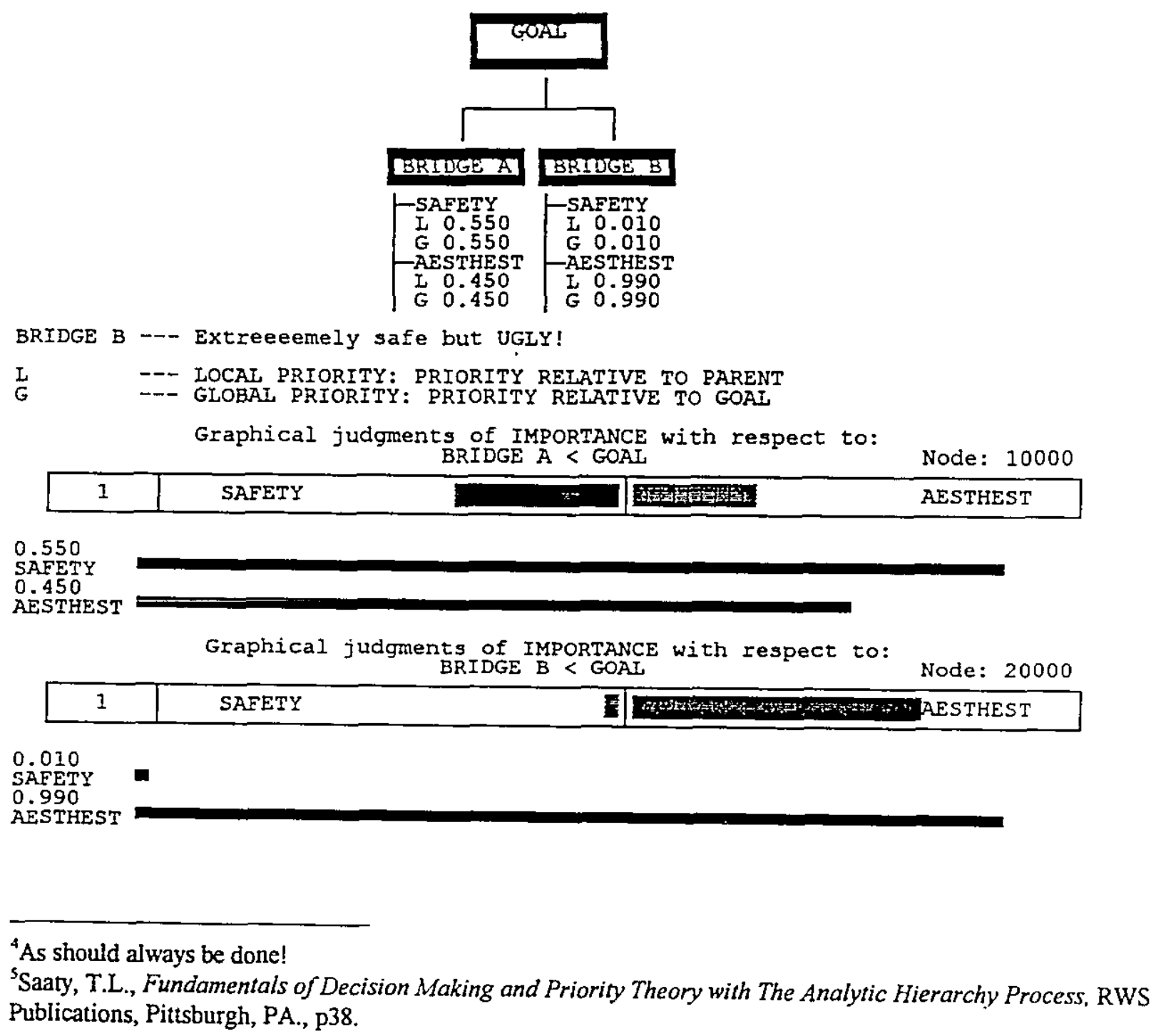


The resulting priority vectors, together with the priority vectors of the preference of the alternatives 'with respect to each criterion, are processed in a 'supermatrix' as follows:

$.00 .00 .55 \quad .01$

.00 .00 .45 .99

$.45 .85 .00: 00$

$.55 .15 .00 \quad .00$

The final priorities for both the criteria and alternatives are obtained by multiplying this matrix by itself several times until the columns stabilize and become identical in each block ${ }^{6}$ :

$.39 .39 \div .00 .00$

$.61 .61 \div 00: 00$

$.00 .00 .70 \cdot .70$

$.00 .00 \div 30: 30$

Synthesis of Leaf Nodes with respect to GOAI

BRIDGE A 0.696

BRIDGE B 0.304

BRIDGE A -- Extremely safe and BEAUTIFUL

BRIDGE $B$--- Extreeeemely safe but UGLY!

The choice and priorities are in very close agreement with those obtained above using the bottom up approach without feedback.

\section{CONCLUSION}

It is possible to arrive at similar results using either a bottom up approach where feedback occurs in the decision makers thought process, or a formal methodological approach where feedback is modeled in a supermatrix of priority vectors. Feedback is deeply ingrained in human functioning. Our ability to move from one part a room to another without falling over pieces of furniture (or even more remarkably to run, intercept and hit a moving tennis ball before it bounces twice within the confines of the court) rests in our brain's ability to continually process information based on cognition and our senses, and to give the appropriate commands to our muscles. Information is continually fed back so that, for example, adjustments to the current path are made based on our desires about our destination, present position, obstacles in our path, forecast of what will happen, and so on. Halfway across the room we might decide to change our destination realizing that the chair we had started out for will likely be taken by another person by the time we arrive. There is no question that humans can mentally process information

${ }^{6}$ Ibid, p40. 
incorporating feedback. Our ability to make judgments about the importance of criteria or objectives based on our knowledge of alternatives is an example of such feedback.

An increased understanding of what our minds can do easily and what we find dificult will be important so that we can employ the proper balance of cognition and decision aids. Our ability to catch a ball, or (for some humans) to think several moves ahead in a game of chess is truly remarkable. On the other hand, psychologists have shown that the human mind has ver. limited abilities in, for example, its short tẹm memory capability and channel capacity. ${ }^{7}$ We function very well without decision models for the vast majority of our decisions. Yet our everyday decision rules or common simplistic strategies are not adequate for what Janis ${ }^{8}$ calls 'crucial decisions'. Our intuition is more than adequate in selecting the best of two bridges given the two alternatives and two criteria in the above example. However our intuition alone would not be adequate if there were several alternatives and many tradeoffs to consider involving perhaps ten, twenty, or fifty criteria. We need to continue to investigate and learn more about human abilities and limitations in making complex decisions so that we can provide decision support where it is needed and in ways that best augment, rather than replace human thinking.

\section{REFERENCES}

1. Janis. I. L. 1989. Crucial Decisions - Leadership in Policymaking and Crisis Management. The Frce Prcss. Ncw York, N.Y.

2. Miller, G.A., "The Magical Number Seven, Plus or Minus Two: Some Limits on Our Capacity' for Information Processing." Psychological Review, (Vol. 63, No. 2, March 1956).

3. Saaty, T.L., The Analytic Hierarchy Process, RWS Publications, Pittsburgh PA, 1990.

4. Saaty, T.L., Fundamentais of Decision Making and Priority Theory with The Analytic Hierarchy Process. RWS Publications, Pittsburgh, PA.

\footnotetext{
"Miller, G.A., "The Magical Number Seven, Plus or Minus Two: Some Limits on Our Capacity for Information Processing." Psychological Review, (Vol. 63, No. 2, March 1956), p. 81-97 ${ }^{8} \mathrm{Janis}$, I. L. 1989. Crucial Decisions - Leadership in Policymaking and Crisis Management, The Free Press, New
York, N.Y.
} 